\title{
SUbVERSIONES, COLABORACIONES Y REDES. A PARTIR DE PROYECTOS Y EXPERIENCIAS impulsadas por Santiago Cirugeda
}

\author{
Subversions, Collaborations and Networks. Based on Projects \\ and Experiences Instigated by Santiago Cirugeda
}

\section{Ramon Parramon Arimany \\ Director ACVic Centre d'Arts Contemporànies}

RESUMEN: Este texto pretende analizar la construcción de procesos colaborativos y de articulación de redes de trabajo, a partir de algunas experiencias impulsadas por Santiago Cirugeda entre finales de los años $90 \mathrm{y}$ hasta la segunda década del 2000. Se ha utilizando una entrevista realizada en 2004 y la publicación que lleva por título Arquitecturas Colectivas. Camiones, Contenedores y Colectivos. La publicación recoge proyectos realizados entre 2007 y 2010, y hace referencia al interés y la deriva de su trabajo hacia la articulación de lo colectivo. Un proyecto que impulsó la configuración de una red de personas y colectivos, que a partir de 2010 se denominó como Arquitecturas Colectivas. Aglutina a numerosos grupos, asociaciones o colectivos de arquitectura y arte existentes en España, que trabajan desde diversas vertientes pero con un interés común por generar prácticas culturales alternativas, y con el objetivo de promover la construcción participativa en el entorno urbano. Los proyectos impulsados, durante estos años, por Cirugeda, constituyen el ejemplo de un trabajo que adquiere una perspectiva sistémica. En este caso lo sistémico toma forma a partir de la construcción de redes y la organización de colectividades diversas, que operan desde la voluntad de incidir en el espacio de lo social, mediante la configuración y uso de códigos abiertos y replicables.

PalABRAS ClaVe: prácticas colaborativas, arte, espacio social, redes. 
RESUM: Aquest text pretén analitzar la construcció de processos col-laboratius i d'articulació de xarxes de treball, a partir d'algunes experiències impulsades per Santiago Cirugeda entre finals dels anys 90 i fins a la segona dècada del 2000. S'ha utilitzat una entrevista realitzada el 2004 i la publicació que porta per títol Arquitecturas Colectivas. Camiones, Contenedores y Colectivos. La publicació arreplega projectes realitzats entre 2007 i 2010, i fa referència a l'interès i la deriva del seu treball cap a l'articulació del col·lectiu. Un projecte que va impulsar la configuració d'una xarxa de persones i col·lectius, que a partir de 2010 es va denominar Arquitecturas Colectivas. Aglutina nombrosos grups, associacions o col-lectius d'arquitectura $\mathrm{i}$ art existents a Espanya, que treballen des de diversos vessants però amb un interès comú per generar pràctiques culturals alternatives, i amb l'objectiu de promoure la construcció participativa en l'entorn urbà. Els projectes impulsats, durant aquests anys, per Cirugeda, constitueixen l'exemple d'un treball que adquireix una perspectiva sistèmica. En aquest cas el sistèmic pren forma a partir de la construcció de xarxes i l'organització de col-lectivitats diverses, que operen des de la voluntat d'incidir en l'espai del social, mitjançant la configuració i ús de codis oberts i replicables.

Paraules Clau: pràctiques col·laboratives, art, espai social, xarxes.

ABSTRACT: This paper aims to analyse the construction of collaborative processes and articulation of networks based on some of the experiences instigated by Santiago Cirugeda between the end of the 1990s and the second decade of the new century. We draw on an interview with Cirugeda from 2004 and the book entitled Arquitecturas Colectivas. Camiones, Contenedores $y$ Colectivos, which describes projects undertaken between 2007 and 2010 and refers to the interest and shift in his work towards articulating the collective. This project led to the formation of a network of people and collectives that in 2010 became known as Arquitecturas Colectivas. It brings together numerous groups, associations and collectives from the fields of architecture and art in Spain, all working from different angles but with a shared interest in generating alternative cultural practices and aiming to promote participatory construction in the urban environment. The projects Cirugeda instigated during these years are an example of work that takes on a systemic perspective. In this case the systemic is seen in the way networks are built and diverse collectives orga- 
nised, all inspired by the desire to make an impact on the social space by configuring and using open, replicable codes.

KEYWORDs: collaborative practices, art, social space, networks.

\section{Introducción}

E ste texto toma como caso específico el trabajo impulsado por Santiago Cirugeda, para abordar el tema de una transición de proyectos de carácter subversivo a otros que responden a una lógica sistémica, fundamentada en procesos colaborativos y creación de redes. El artículo se divide en dos grandes apartados, el primero con el nombre «Estrategias subversivas» se refiere a la primera etapa en la que desarrolla las cuestiones de legalidad, ilegalidad o alegalidad en las intervenciones en el espacio de la ciudad. El segundo apartado denominado «Estrategias colaborativas», se refiere al periodo en que lleva a cabo una serie de proyectos conjuntamente con colectivos que operan en distintos lugares de España. Las revisiones de lo legal y sus articulaciones colectivas se mezclan con la potenciación proactiva de la ciudadanía.

Santiago Cirugeda es un arquitecto que inicia su trayectoria en 1995, y después de siete años de trabajo en solitario, funda el estudio Recetas Urbanas, desde el cual sigue trabajando con un equipo de personas que, de manera puntual o de una forma más prolongada, han colaborado en las propuestas que ha llevado a cabo. En sus inicios quedan proyectos como la ocupaciones sistemáticas del espacio público mediante el uso de contenedores, o la construcción de prótesis en fachadas de edificios, patios, cubiertas e incluso solares abandonados.

De forma progresiva, los proyectos de Santiago Cirugeda se han sofisticado, en el sentido de que han actuado de detonante a la hora de generar espacios de trabajo colaborativo, de buscar la implicación y participación de las personas en proyectos surgidos de talleres o de la construcción de una configuración en red. Podríamos decir que ha pasado de un trabajo desarrollado desde una articulación individualizada, a un proceso fundamentado en la construcción colectiva de estructuras. Y ya en etapas más recientes, en la configuración de sistemas más complejos en los que la arquitectura articula espacios fruto de deseos colectivos, donde los procesos de construcción se generan en entornos participativos. 


\section{Estrategias subversivas}

El concepto «estrategias subversivas» ha sido utilizado por Cirugeda desde sus inicios, refiriéndose básicamente a las ocupaciones urbanas que ha implementado, o que ha propiciado para que otras personas las lleven a cabo. Se trata de ocupaciones temporales de espacios con el objetivo de señalar, evidenciar una problemática, un conflicto existente, o para llevar a cabo actuaciones en un determinado contexto y desde una articulación colaborativa.

Una «estrategia» consiste en un conjunto de acciones dirigidas a conseguir un determinado objetivo. Es una palabra usada habitualmente en los ámbitos militares, políticos o empresariales, donde no conviene evidenciar las decisiones o los caminos que se van a seguir. La estrategia toma valor cuando se han conseguido los resultados perseguidos. Dar a conocer con antelación las acciones y los logros pone en riesgo la eficacia de la operación, y por tanto el sentido de la estrategia. El término «subversión» se refiere a un proceso en que los valores y principios de un sistema establecido se invierten y se relaciona con una alteración, un conflicto o una revuelta. Por tanto, la combinación «estrategias subversivas» promete un objetivo que no dejará impasible. Y las ocupaciones urbanas, aunque temporales, han constituido una práctica emergente que ha mantenido el interés de muchas personas y colectivos que persiguen transformaciones alternativas en el normativizado territorio urbano.

La primera de las entrevistas en que nos basamos para introducirnos a lo que hemos llamado estrategias subversivas fue realizada en 2004, y parte de ella se publicó en el artículo Outskirts Artist. ${ }^{1}$ Desde las primeras intervenciones en el espacio público en Sevilla, Santiago Cirugeda se sitúa a sí mismo en las afueras del arte, pero también en los alrededores de la arquitectura. Es y quiere ser arquitecto, más que artista, pero utiliza conscientemente la etiqueta de artista como parte de su estrategia subversiva. Es un intruso que utiliza el arte para convertirse en activista, consciente de que opera dentro de las reglas indisciplinadas que le posibilita el arte. En el artículo, defiende un tipo de arte que requiere salir de su propia disciplina para implicarse con otras, y de esta forma poder actuar directamente sobre lo social. Y su forma de hacerlo es mediante la activación de herramientas que se ponen a disposición de la ciudadanía para que puedan ser utilizadas de forma subversiva por aquel que lo desee.

1. Parramon, R. (2008): «Outskirts Artist» en The/End Magazine. Parallel Project n.1. Milano: Direct Arquitecture. Politics and Space. 
Los ejemplos que yo hago son [...] de un uso razonable y razonado de la legislación, animando a la gente a que pueda usarlo; que luego la gente podrá malversarlo igualmente. Propongo nueva vías de trabajo personal. Yo ya conozco a muchos artistas que lo están utilizando, que están trabajando sobre la legalidad como base teórica o intelectual para debatirla, o como base social y urbana. Me preocupo mucho en que se difunda por prensa cotidiana o incluso en la página web que se llama «Recetas Urbanas» (www.recetasurbanas.net). La primera frase que sale en esta página web es que cualquiera puede utilizar este contenido. Cualquiera puede reapropiarse de las ideas que se presentan y reproducirlas. ${ }^{2}$

Desde el artículo se abre un preámbulo hacia el arte que se posiciona social y políticamente. También hacia maneras de construir experiencias y formatos que pueden activar prácticas culturales relacionadas con múltiples realidades existentes. Hacia un tipo de prácticas artísticas que declinan el habitual estatus social y político que las protege, para devenir una actividad articulada en una trama social y política, adquiriendo un rol activo y en interacción con otras prácticas. En este sentido, se remarca la labor de instituciones o programas independientes que posibilitan la existencia de estrategias dirigidas a activar prácticas creativas en territorios concretos. Son programas que permiten desplegar procesos de trabajo extendidos en el tiempo, una inmersión en el lugar y la posibilidad de desarrollar proyectos en el espacio público interactuando con cuestiones de carácter social. Una introducción a lo que se ejemplifica con los proyectos de Santiago Cirugeda.

Se alerta asimismo de la proliferación de propuestas que promueven una implicación social y política a través de diferentes modos de utilizar el trabajo de los artistas. Es decir, la aparición de posibilidades de canalizar dichos trabajos desde el impulso de programas de carácter social, que entienden el trabajo artístico como una herramienta para desplegar la organización de talleres u otras actividades, que en muchos casos son una mezcla de dinamización social y creatividad aplicada. Este tipo de prácticas impulsadas desde la dinamización social han crecido en paralelo a otras que parten de la iniciativa de los artistas, mediante la existencia de programas concretos o desde instituciones artísticas. Un crecimiento, en el contexto español, que se despliega por diversos lugares desde principios del 2000. Se potencian las prácticas que promueven la participación de los individuos, que inciden en la función crítica del arte, o que per-

2. Parramon, R. (2008): Op. cit., p. 36. 
siguen introducir dinámicas de cambio en relación con el contexto, con los públicos o incluso en las políticas culturales.

\subsection{Las primeras «Recetas urbanas»}

Una de las cuestiones importantes es que el trabajo de Santiago Cirugeda, ya se entienda como obra de un arquitecto o de un artista, sobre todo en la primera fase, es la relación que mantiene con el contexto local. Lo local adquiere una importancia especial, ya que las normativas o las estructuras que pretende subvertir deben ser analizadas desde lo local.

En sus inicios, la mayoría de proyectos se realizan en Sevilla. A pesar de que es invitado a participar en exposiciones y bienales internacionales, en muchos casos participa en ellas haciendo referencia a lo desarrollado en la ciudad donde habita, y donde tiene ubicado su estudio. Sevilla es el lugar donde ha puesto en práctica las primeras subversiones urbanas, y son las que se recogen en la primera publicación Situaciones Urbanas, ${ }^{3}$ un libro que presenta catorce situaciones concretas, donde explica cómo ha sido capaz de realizar propuestas que buscan alterar la dinámica de la ciudad mercantilizada, y proponer alternativas para convertirla en un lugar más habitable. En esta publicación se detallan las estrategias que le han permitido reinventar proyectos que afectan tanto a la vivienda, como al museo, la universidad, los centros sociales o el espacio público. A esta primera fase le corresponde un periodo de expansión y articulación de metodologías y formas de afrontar la práctica, siempre fundamentada en la experiencia vinculada al contexto local y vivencial. De hecho, fue entonces cuando iniciamos una relación personal y profesional. ${ }^{4}$

Otro aspecto importante, como parte de su estrategia para afrontar los proyectos, es la relación con la prensa. Cada una de las acciones que impulsa conlleva un alto grado de noticiabilidad que aprovecha para dar visibilidad y eficacia al proyecto. Uno de los primeros fue la «Casa Insecto». En él encontramos estos ingredientes bien ensamblados. El proyecto se vinculaba a una reclamación vecinal impulsada por el colectivo Alameda Viva, que protestaba contra un plan urbanístico que preveía la tala de unos árboles

3. Cirugeda, S. (2004): Situaciones Urbanas. Barcelona: Editorial Tenov.

4. En 2001 realiza el proyecto «Molino de Calaf», junto con Lara Almarcegui en Idensitat, para la población de Calaf. También este 2001 participa en una de la ediciones del festival EME3 que se realiza en el Centro de Cultura Contemporánea de Barcelona, donde presenta la «Casa Insecto», uno de los ejemplos iniciales de estrategias subversivas. 
centenarios. Gracias a la visibilidad que adquiere la propuesta de Cirugeda, consigue atraer a los medios de comunicación y aparecer en los periódicos. Un elemento más que se suma a la estrategia subversiva que propone.

A principios del 2000 su carrera se expande hacia otros contextos locales, en unos casos presentando lo desarrollado en Sevilla y en otros adaptándose a los nuevos contextos. Progresivamente, su trabajo se configura a partir de una estrategia a largo plazo. Los proyectos adquieren fuerza en la suma de intervenciones, en las implicaciones con colectivos, en los numerosos talleres que se extienden casi las 24 horas del día. Su labor entregada e incansable está orientada a convertirse en una especie de servicio público, poniendo el dedo en la llaga en las carencias sociales, los vacíos legales y activando un conjunto de estrategias que sólo tienen sentido si son acogidas por colectivos que le den continuidad.

La entrevista de la que partimos se realizó a mediados de 2004 y nos permite analizar cuestiones clave para entender sus inicios. Sus comentarios siguen vigentes a través de la imparable actividad que ha desarrollado desde finales de los 90. Su testimonio contribuye a dibujar la necesaria existencia de planteamientos que permiten producir y poner de relieve el carácter de servicio público que, bajo ciertas circunstancias, pueden alcanzar las prácticas artísticas.

En primer lugar vamos a ver de qué manera entiende este concepto de legalidad en relación con el espacio público. A lo largo del desarrollo profesional de su trabajo, ha hecho hincapié en la importancia de que el ciudadano acuda a las administraciones locales y conozca las normativas y las ordenaciones locales. En la medida que la gente conozca cuáles son sus derechos y cuáles sus limitaciones, podrá intervenir en la ciudad o en el desarrollo de un proceso creativo de manera distinta de cómo lo harían sin esos conocimientos. Para él es clave que la gente conozca, o por lo menos que queden claros los mecanismos que permiten que adquiera consciencia de las reglamentaciones legales que regulan sus posibilidades de acción. «La ilegalidad que aparentemente es invisible, es latente. Habitualmente el artista tiene una excepción legal». Ésta es una consideración interesante, pues tiene que ver con su particular relación ente arte y arquitectura. Para él, el arte o el artista pueden pasar por encima de la legislación, porque tienen un permiso explícito de la institución para desarrollar su trabajo. La arquitectura se debe a una reglamentación urbana y a una responsabilidad civil que condiciona su trabajo. Este conocimiento que el arquitecto tiene, o que debería tener, de la normativa, lo traslada al ciudadano, es decir, empodera al ciudadano para que adquiera los conocimientos

5. Parramon, R. (2008): Op. cit., p. 38. 
sobre la reglamentación que le afecta. Conocerla le permitirá actuar en consecuencia, desde la legalidad, la ilegalidad o los vacíos que permiten la legalidad. Se trata de conocer lo que puede saltarse o no. Es decir, dar los conocimientos necesarios al ciudadano para que pueda hacer un uso razonable y razonado de la legislación.

Otra cuestión que nos comenta es su preocupación para que esto se difunda, se transmita, se expanda. Desde la página web «recetasurbanas.net», invita a la gente a que se reapropie de las ideas y del contenido que se explicitan en ella, y que las reproduzcan en otras circunstancias. Aunque algunas aplicaciones de las ideas o «recetas urbanas» propuestas conllevan un grado de responsabilidad que debe asumir quien quiera reproducirlas, y así se evidencia en la web:

ADVERTENCIA Todas las recetas urbanas mostradas a continuación son de uso público, pudiendo ser utilizadas en todo su desarrollo estratégico y jurídico por los ciudadanos que se animen a hacerlo. Se recomienda el estudio exhaustivo de las distintas localizaciones y situaciones urbanas en las que el ciudadano quiera intervenir. Cualquier riesgo físico o intelectual producido con el uso de las mismas correrá a cargo del ciudadano. Santiago Cirugeda ${ }^{6}$

Ante la pregunta sobre la importancia de realizar un proyecto en un lugar con el cual hay un vínculo establecido, porque es donde se vive habitualmente, y por tanto facilita la conexión con el contexto, frente al hecho de trabajar circunstancialmente en contextos menos familiares, nos comenta que nada le impide trabajar en otros sitios. Su trabajo se basa en verificar unas leyes propuestas por políticos o técnicos de la administración pública, que una vez implantadas, se impregnan de la realidad social y cultural del lugar.

Él conoce perfectamente cómo funciona esta ley en su entorno de Andalucía, y sobre todo en Sevilla, donde puede entender las faltas y las carencias de esta ley en el uso social de la calle. Pero puede extrapolarlo a Madrid, Cataluña o Milán. Para él es necesario el lugar no sólo como ente físico, sino como interacción múltiple entre ciudadanos, agentes económicos, agentes culturales o personas anónimas, para entender que este sistema generado está más o menos controlado por la ley. Una ley es una institución, un sistema de control que da beneficios para aquéllos que no tienen fuerza para demandarlo. No es que se persiga abolir la legislación, pero sí que permita ciertos grados de libertad al ciudadano. Modificar aspectos de la ley para que proteja y a la vez conceda libertades. Mostrar los grados de libertad que una ley

6.. $\quad<$ http://recetasurbanas.net $>$ [Consulta: 10 de mayo de 2015]. 
permite, cuando éstos están ocultos, trabajar para que la ley sea más coherente con el entorno social donde se implanta.

Considera que los proyectos que lleva a cabo se acercan a lo que los ciudadanos quieren hacer, y en muchos casos parten de peticiones o reclamaciones vecinales.

\subsection{La replicabilidad de los proyectos}

Las estrategias subversivas de ocupación urbana que plantea, y que es una de las categorías desde las que agrupa sus trabajos, son fórmulas que los ciudadanos pueden realizar, a partir de los vacíos legales que la institución plantea. Que estas ideas o propuestas sean replicadas por otros dependerá de las energías, el interés o la valentía de colectivos ciudadanos para darles continuidad. En su trabajo, la comunicación o el vínculo directo con la población pasa por abordar sus temas cotidianos. Nos habla de propuestas cotidianas que la gente ya tiene previstas. La mayor parte de ellas ya están planteadas por la ciudadanía. Y él actúa como ejecutor de cosas que la gente ya quisiera hacer. En cierta manera, su trabajo se asemeja al que persiguen ciertas formas de arte público, en el sentido de utilizar el espacio en beneficio del ciudadano; él se ve como emprendedor de algo que está en la demanda colectiva.

Otro aspecto que aquí nos interesa es la temporalidad en las intervenciones, o la implicación en procesos expandidos en el tiempo. Pero también las presiones de temporización que suelen infundir los programas que impulsan proyectos de intervención en el espacio público. Casos concretos como los de «Andamio», «Proyectar con luces» (1998) o «Casa Insecto» (2001), que corresponden a su primera época, en la que despliega de forma experimental una manera de hacer y de intervenir en el espacio.

Mediante este tipo de trabajos se anticipa a cualquier encargo, nadie condiciona ni aplica presión sobre cómo y cuándo hay que formalizar el proyecto. Pero es a posteriori cuando sus actuaciones deben combinar la autogestión de los proyectos con los encargos. Nos comenta que se considera un mal profesional del arte, porque aunque suele participar en bienales o eventos a los que es invitado, no da la seguridad ni la garantía de acabar finalizando el proyecto en el tiempo exigido. Considera que el programa nunca debe obligar ni exigir, aún reconociendo que a nivel curatorial es difícil de justificar, pero defiende la opción de plantear un programa abierto de manera que los tiempos se puedan adaptar y modificar a los procesos. Más con una pretensión de inserción real de estos procesos, que con actuaciones predefinidas 
y ajustadas a unos tiempos programáticos. El programa debe existir pero debe ser abierto: procesos abiertos y temporalidad adaptable.

Las producciones artísticas en las que me interesa participar son las que posibilitan un proceso abierto, que no finaliza en un periodo concreto de tiempo. Que el trabajo siga latente en el entorno urbano en que has trabajado. Que haya dejado la semilla para que algo cambie. No me creo los programas de arte que acaban en el momento en que se publican. Me interesan procesos que pueden continuar los mismos ciudadanos. Esto va más allá de la historia del objeto que tiene un momento limitado. Incluyendo en ello la pérdida de control por parte del artista que ha generado el proceso. Un proceso que tú nunca vas a terminar y que al ser entregado a lo público tienes la certeza de que va a ser manipulado y cambiado, con la idea previa de que esto es lo que te interesa. A nivel de urbanismo es eso que nunca vas a dibujar porque existirá siempre. A nivel de arte aquel proceso que tú una vez desapareces, queda. $^{7}$

Ya en sus inicios podemos considerar que el trabajo de Cirugeda está ubicado en esta frontera entre el arte y la arquitectura, unos intersticios que le permiten actuar desde un lado u otro de la frontera disciplinaria. Pero a su vez en unos límites que inicialmente pueden no ser reconocidos por ninguno de los ámbitos disciplinarios. Él procede y se reconoce en la arquitectura, aunque su trabajo ofrece también interés en el ámbito del arte, en la práctica del comisariado o incluso en la legislación urbana. Conllevan una alta carga política, ya que las opciones que plantea son en clave transformadora.

Él es crítico con la labor del artista, por su falta de compromiso a largo plazo, y con el propio sistema artístico, el cual exige al artista que periódicamente realice un proyecto, entrando en una dinámica de producción constante y de exigencia continua de actividad. Hay muchos proyectos que pretenden intervenir o incidir en aspectos sociales, dando una respuesta crítica al contexto, y la premura de los tiempos, de los programas que los acogen, apenas les concede unos días para articular cosas que requieren un tiempo y un conocimiento mucho más profundo. Ya no se trata sólo de que dure, sino de que tenga una repercusión real en el foro, o en el contexto desde el que se articula el trabajo. En este sentido, él apuesta por programas que permitan plantear los proyectos con una perspectiva a más largo plazo.

7. Parramon, R. (2008): Op. cit., p. 39. 
No sé si podría existir un programa curatorial planteado desde esta perspectiva de largo plazo, con realizaciones de workshops, etc. También es verdad que para mantener estos proyectos debes contar con una cierta estabilidad. Es necesaria una involucración personal pero también un respaldo institucional. ${ }^{8}$

\section{Estrategias colaborativas}

A raíz de la publicación Arquitecturas Colectivas. Camiones, Contenedores y Colectivos, ${ }^{9}$ vamos a analizar cómo se hace evidente y se consolida, en su forma de trabajar, el interés por las estructuras colectivas y colaborativas. Lo que la publicación recoge es el ejemplo de una manera de hacer que cuenta con la implicación de numerosos grupos, asociaciones y colectivos existentes en España, los cuales trabajan desde diversas vertientes pero interesados en generar prácticas culturales alternativas. La publicación constituye además una manera de abordar y dejar constancia del génesis de la plataforma Arquitecturas Colectivas, en la que Santiago Cirugeda, junto con otros arquitectos como David Juárez de Straddle3 o Diego Peris de Todo por la Praxis, así como otros colectivos, acabaron dando forma e impulsando esta plataforma abierta que se reúne por lo menos una vez al año, desde 2010.

\subsection{Proyecto «Camiones, Contenedores y Colectivos». La dimensión social de la reparación}

La manera más simple de efectuar una reparación es desarmar, encontrar lo que falla, arreglarlo y luego devolver al objeto su estado anterior. A esto se le podría llamar reparación estática; es lo que se da, por ejemplo, cuando se reemplaza el fusible quemado de una tostadora. Una reparación dinámica cambiará la forma o la función del objeto, que es lo que ocurre si se sustituye un filamento roto de la tostadora por otro de mayor potencia, de modo que el aparato pueda tostar el pan tanto en rebanadas como en bollos. ${ }^{10}$ (Richard Sennett)

La artesanía es el impulso humano duradero y básico de hacer las cosas bien. Así lo ha definido Richard Sennett en su libro El artesano. En él ha indagado en la

8. Ibíd., p. 40.

9. Cirugeda, S. et al. (2010): Arquitecturas Colectivas. Camiones, Contenedores, Colectivos, Sevilla: Ed. Vibok.

10. Sennett, R. (2009): El artesano. Barcelona: Editorial Anagrama. 
estrecha conexión entre la cabeza y la mano. Plantea que las habilidades empiezan como prácticas corporales y que la comprensión técnica se desarrolla a través del poder de la imaginación. Existe un primer conocimiento que se adquiere con las prácticas manuales a través del tacto y el movimiento, y en una segunda instancia, la imaginación se encarga de hacer algo, de dar forma a las cosas a partir del dominio del lenguaje y la técnica. En el capítulo «Herramientas estimulantes» habla de la reparación dinámica, aquélla que es capaz de volver a poner en funcionamiento algo pero transformándolo, adquiriendo una nueva forma o función.

Otro concepto relacionado es el de ingeniería reversible o inversa, que consiste en obtener información de un producto con la finalidad de determinar de qué está hecho, saber cómo funciona y poder reorganizarlo con nuevos elementos o contenidos. Constituye, en esencia, un proceso para innovar que a menudo se aplica al software o al diseño de producto. La ingeniería reversible o inversa no deja de ser un método de reparación dinámica en el que la habilidad manual está al servicio de la imaginación para reorganizar, remezclar, reconstruir, redefinir cosas y conceptos con una apariencia nueva.

El trabajo que viene desarrollando Santiago Cirugeda con el equipo Recetas Urbanas no deja de ser un trabajo artesanal de reparación dinámica. Con el proyecto «Camiones, Contenedores y Colectivos», ha reciclado contenedores que luego ha ofrecido a colectivos o agrupaciones de diferentes ciudades españolas. Cada grupo ha acogido una o varias de las casas prefabricadas, desmanteladas de un antiguo asentamiento gitano. Cada colectivo constituye, en esencia, el contenido del proyecto y pone la imaginación necesaria para dotar de un nuevo uso a los habitáculos. El contenedor es lo que se ha trasladado y se ha tuneado para adaptarse a las actividades propias de cada uno. Los colectivos, al transformar estas antiguas viviendas actúan además como un artesano que recicla, repara e innova, de manera que cada uno de estos contenedores vive una profunda transformación y actualización. Que Santiago Cirugeda es un artesano nadie lo duda; de hecho, una parte importante de su actividad es poner tornillos. Las personas que han trabajado con él, ya sea en Granada con Aula Abierta, en Málaga en la Facultad de Bellas Artes, o en cualquiera de las múltiples construcciones que ha creado o recreado, lo saben.

La reparación dinámica sirve para reconstruir o diseñar proyectos de intervención así como políticas culturales o urbanísticas. Cada uno de estos artefactos constituye una herramienta intermediaria que persigue un objetivo de transformación, ya sea para introducir cambios en las ordenanzas municipales de una ciudad, para facilitar un espacio educativo alternativo, para revalorizar el conocimiento autoconstructivo de la gente que habita en un asentamiento informal, para mostrar vacíos legales 
que permiten la ampliación de vivienda en azoteas, o también para ayudar a que los colectivos puedan disponer de un espacio, así como valorar su capacidad organizativa y de autogestión.

A lo largo de un periodo de trabajo de diversos años, ha ido forjando una estructura organizada con capacidad de transformación política y social. Desde sus ocupaciones temporales de espacios abandonados, las ampliaciones alegales de vivienda, las ocupaciones de azoteas, el reciclaje de espacios, al reparto de viviendas por parte de colectivos de diversas ciudades españolas, se observa una clara intención política que se resume en potenciar y fomentar la organización ciudadana para establecerse como acción política alternativa.

El proyecto «Camiones, Contenedores y Colectivos» promueve la articulación de una red de colectivos, cada uno con su estructura y actividad independiente. Los contenedores se han distribuido, inicialmente, entre trece colectivos. El proceso ha permitido varios encuentros para compartir y discutir sobre problemas de gestión, de recursos, de posicionamientos políticos, o de estrategias que puedan compartirse. Uno de los elementos que aporta esta red es que da visibilidad a una serie de colectivos que trabajan con la autogestión y la autoconstrucción para participar enérgicamente en la creación de su entorno cultural y social. Reclaman una forma alternativa de entender la participación ciudadana en el contexto en el que trabajan. Se posicionan como una estructura rizomática, autorganizada detrás del poder económico y político. Una estructura ramificada que propone actuar escapando de la necesidad de control que tienen los gobiernos locales.

\subsection{Sobre la participación, realidades y ficciones}

La participación ciudadana es algo reclamado desde la sociedad civil y que con el tiempo se ha implementado en la mayoría de administraciones. Esto ha generado unos protocolos que se repiten a la hora de efectuar cualquier plan de transformación. Son estrategias que se reproducen de forma mimética sea cual sea el contexto de actuación. Cada uno de los colectivos que forman parte de Arquitecturas Colectivas tiene un plan alternativo, constituyen una red de reparadores dinámicos de los protocolos participativos, el trabajo social y la creatividad aplicada. Y esto puede definirse como estrategias políticas de acción colectiva, ya que pueden transmitir su conocimiento a otros ciudadanos.

El desarrollo de procesos participativos es común en numerosas actividades promovidas tanto por técnicos de la administración como por pequeñas agrupaciones o 
por prácticas puntuales. Cualquier plan estratégico que se precie debe impulsar un proceso participativo, si no probablemente carecerá de legitimidad. Habitualmente, se entiende como un derecho del ciudadano para complementar, mediante la democracia directa, aquello que no queda atendido por la democracia representativa.

Sin embargo, cuando se pone en marcha un proceso participativo parece que se reclama al ciudadano su presencia como si se tratara de un deber. No participar es quizás también una forma activa de participar, gritando en silencio que a lo que se llama a participar no interesa, quizás porque quien llama no nos transmite la suficiente confianza. También es verdad que el ruido, las distracciones, la comodidad y la vagancia juegan en contra a la hora de tomar partido por algo, y nuestra forma de estar en el mundo se reduce a ser espectadores pasivos. A veces, la participación es una forma de entretenimiento utilizada para decidir cuestiones banales y parciales. Por ejemplo, sobre un color, una selección de proyectos de diseño de un espacio público, u otras intervenciones de carácter decorativo. Cuando esto se produce, el ciudadano puede no sentirse motivado porque se da cuenta del escaso valor de sus decisiones, y si decide participar no siempre conoce o cuenta con las herramientas negociadoras que el proceso requiere.

Son muchos los que quieren o hablan de participación, pero no siempre se consigue y cuando se logra a veces molesta. La participación conlleva un componente crítico y autocrítico, y esto es algo que no se asume fácilmente. Requiere de habilidades negociadoras, comunicativas y de la capacidad de desprender confianza para llevarla a cabo. La participación es un arma de doble filo, una herramienta perversa que la socialdemocracia ha puesto en funcionamiento con el fin de promover una sociedad pacífica y democrática, a pesar de que el espacio social en que debe articularse se basa en el conflicto. La articulación de participación y conflicto no es de fácil resolución.

En algunos ámbitos del arte también está muy presente la participación. Numerosos artistas y colectivos pretenden incorporar en sus prácticas estrategias participativas con el fin de incidir en el espacio social. Igual que en otros campos, a veces es una realidad y en otras es una ficción. De todas formas, en el arte contemporáneo ha habido intentos de romper la comunicación unidireccional con el público. Así, en los años 60 se iniciaron algunas de las prácticas que posteriormente se han ido explorando. En un primer momento era prioritario abrir la participación del público a la obra de arte. De esta forma aparecen las obras participadas, donde el evento temporal, la performance o la disolución del arte con la vida toman una vía expandida de interacción. 
Sin embargo, esto es aún insuficiente si lo que pretendemos es disolver la práctica artística en múltiples agentes participantes y aprovechar la creatividad de las personas para promover una acción colectiva. Todos podemos desarrollar nuestra creatividad si encontramos el entorno adecuado para poder dedicar tiempo, crear las redes necesarias y canalizar la energía en algo potencialmente transformador.

En 2009 estuve implicado en la organización de un seminario donde la relación entre creatividad, acción colectiva y prácticas artísticas se ponían en relación con el barrio. Estas cuestiones fueron tratadas en los dos días de debate desde el cruce de diversas disciplinas: el arte, la arquitectura, el trabajo social y la política. ${ }^{11}$

Los debates que se generaron fueron intensos y contundentes a la hora de reconocer que estamos ante un panorama cambiante en lo referente a la acción colectiva, y que reclama una necesidad de expandir los procesos de creatividad más allá de las disciplinas que tradicionalmente se han reconocido como capitalizadoras de ella. Abordar ciertas prácticas desde la perspectiva de las disciplinas se torna obsoleto y carece de eficacia, si lo que se pretende es expandir la capacidad de acción con que puede dotarnos la creatividad como herramienta y arma política. Esa herramienta la posee todo ciudadano desde el momento que se pone en circulación y en relación con los demás. Expandir la capacidad creativa, poder dedicar el tiempo y el esfuerzo necesario en algo que pueda articularse colectivamente, ser capaz de infundir la confianza necesaria para poder compartir proyectos, adquirir la capacidad de comunicar para que los demás comprendan la necesidad de involucrarse en un proyecto. Todo esto es ahondar en las estrategias de algo que corre el peligro de tornarse demasiado nombrado: la participación.

La participación es algo que planeó por encima de todas las presentaciones y debates surgidos. Las dudas sobre cómo abordarla, dónde aplicarla, cuándo impulsarla son menores si no tenemos definidos los porqués. Si no se tiene claro por qué es necesario activar un proceso participativo, qué es lo que se puede ofrecer y qué se quiere obtener; si no se conoce el espacio social donde se va a realizar, si no se hace transparente el proceso, mejor no enredar al personal. Si el objetivo de enredar es multiplicar la capacidad crítica, posibilitar complicidades, generar procesos de intercambio de experiencias y promover algún cambio que afecte al contexto, entonces

11. El seminario organizado por Idensitat tenía por título «iD Barrio. Creatividad social, acción colectiva y prácticas artísticas». Se realizó en noviembre de 2009 dividido en dos partes, una en Calaf tomando como elementos de análisis las pequeñas y medianas ciudades; y otro en Barcelona (La Capella), analizando proyectos e intervenciones en el contexto urbano, relacionándolo con la transformación de la ciudad y los movimientos sociales. Para más información ver http://idensitat.net. 
estamos potenciando la creatividad social para aplicarla a acciones colectivas. Da igual que se active desde las prácticas artísticas, las prácticas de dinamización sociocultural o las arquitecturas colectivas, ya que el objetivo es incidir en lo político desde abajo hacia arriba. De hecho, es una acción política porque engendra un potencial y una voluntad de transformación, ejerciendo el derecho que todo ciudadano tiene de participar en la construcción del mundo en el que vive. Para unos es el barrio, para otros la ciudad y para otros el continuo transitar entre distintos lugares.

Participar en estos procesos de transformación es un derecho, tal y como ha señalado David Harvey: «el derecho a la ciudad no es simplemente el derecho de acceso a lo que ya existe, sino el derecho a cambiarlo a partir de nuestros anhelos más profundos»». ${ }^{12}$ Pero también nos recuerda que es un territorio de confusión, de conflictos y violencia, tal y como nos ha evidenciado la historia. La calma y el civismo han sido la excepción. La ciudad y los barrios han sido escenario de destrucción creativa, pero han sobrevivido, y a partir de nuevas acciones creativas se han reconstruido, reinventado e incluso han planteado innovaciones. Todo proceso participativo conlleva esta práctica a la vez creativa y destructiva. Es por esto que asusta y los gestores políticos tienden a ejercerla bajo control. La concejalía de participación ciudadana existe en la mayoría de municipios, más que como instrumento para potenciar la participación, como forma de control y domesticación de la misma.

En los trabajos que impulsa Santiago Cirugeda, la participación está completamente presente. No es una participación fundada en lo teórico, sino en la vertiente activa del diseño y la construcción de los espacios, los habitáculos o las estructuras. La mayoría de talleres tienen un componente de edificación muy fuerte. Por ejemplo, el que se organizó en el proyecto Aula Abierta en Granada consistía en desmontar una nave y volverla a montar con otra forma en otro lugar.

El taller que se realizó para formar a las personas participantes, llevaba por título: «Del seguro de responsabilidad civil al tornillo autorroscante». Incitaba a los estudiantes a tomar parte en la construcción de la obra. La cuestión experiencial, la implicación directa y las negociaciones que se establecen en una dinámica constructiva colaborativa y participativa, constituyen una particular aplicación que va más allá de las metodologías clásicas de participación. Se conecta con formas de acción directa, al aprender haciendo, o de motivación a través de la implicación y la pertenencia a un proyecto colectivo.

12. Harvey, D. (2008): El derecho a la ciudad. Kaosenlared.net $<$ http://www.kaosenlared. net/noticia/el-derecho-a-la-ciudad $>$ [consulta: 30 de noviembre de 2014]. 


\subsection{De las «recetas urbanas» a las herramientas colectivas}

«Camiones, Contenedores y Colectivos» se asemeja a un proyecto artístico en el sentido que incorpora tácticas de acción cultural y componentes estéticos. Pero a la vez es un proyecto arquitectónico en el sentido que provee de habitáculo a quien lo necesita. Se asemeja, además, a un plan de desarrollo para el incentivo del empleo, pues provee de infraestructuras básicas a personas con iniciativa. También tiene algo en común con el proyecto de expansión de una empresa que amplía sus franquicias en distintos lugares del territorio.

Es un poco de todo esto, mezclado con el espíritu de los trabajos iniciales de Santiago Cirugeda, caracterizados por la voluntad de dotar de herramientas que estimulen al ciudadano. Siempre le ha interesado que los ciudadanos conozcan sus derechos y deberes, de manera que puedan reinterpretarlos y buscar brechas legales para activar sus propios proyectos. Las Recetas Urbanas han consistido en posibles fórmulas que han jugado en el campo de la alegalidad, con espíritu de incentivar la participación para que las personas tomen partido en el espacio social y político.

El propio concepto al que se refiere con el nombre de Recetas Urbanas ha ido evolucionando con el tiempo. En un principio constituían el conjunto de proyectos que Cirugeda iba desarrollando. Era como el contenedor que daba sentido al conjunto de pequeñas acciones. Actualmente Recetas Urbanas es el estudio, entendido como colectivo de personas que trabajan conjuntamente con Cirugeda. A la vez, mantiene esta referencia inicial entendida como suma de acciones creativas, que progresivamente han ido realizando y recopilando como si se tratara de un menú aplicable a diversos contextos sociales. Estudio entendido no como espacio de trabajo sino como tiempo de conocimiento, como laboratorio de experimentación e investigación colectiva. Y un estudio que, en este caso, se ha expandido a otros muchos colectivos que se han adherido al experimento.

Hal Foster habla de una «promiscuidad de colaboraciones» en un texto donde problematiza los conceptos de participación y colaboración en el arte contemporáneo que, según él, conlleva a generar una «promiscuidad de instalaciones» ${ }^{13}$ que son las que pueden verse en las múltiples bienales. Instalaciones que, a su juicio, aglutinan gran cantidad de textos, vídeos, objetos, ocasionando un efecto más caótico que comunicativo. El arte que se genera en estas circunstancias plantea, en muchos casos, problemas de visualización en los tradicionales espacios de representación. En este tipo de trabajos adquieren importancia elementos como las discusiones, los

13. Foster, H. (2006): «Chat Rooms//2004». En Bishop, Cl (ed.). Participation, 190-195. London: Whitechapel Gallery. Cambridge, Massachusetts: The MIT Press 
encuentros, las vivencias, los acuerdos, etc., todos ellos parte imprescindible del proceso de socialización creativa. Constituyen en muchos casos la propia obra.

Estos procesos no son fácilmente traducibles en el limitado espacio expositivo, aún esencial en el ámbito del arte. Los proyectos basados en procesos colaborativos y participativos no pueden analizarse desde la lógica de la habitual puesta en escena. Forman parte de un territorio de transversalidad que activa nuevas prácticas culturales, las cuales podrán incidir de manera activa en el contexto social.

Creo que en este caso, más que hablar de arte, arquitectura, economía, legislación o de cualquier otra disciplina relacionable con los matices del trabajo Camiones, Contenedores y Colectivos, debemos hablar de acción cultural. Esta consiste, según Teixeira Coelho, en establecer puentes entres las personas y el proyecto, permitiendo que aquéllas participen en el universo cultural. El proyecto actúa de mediador para que las personas se relacionen y desarrollen su dimensión creativa en un ámbito común o compartido. Uno de sus objetivos consiste en disipar la incomunicabilidad social a través de disminuir «la tentación a la inercia y a la pasividad que indistintamente afecta a la mayoría en los tiempos de comunicación de masas». ${ }^{14}$

Plantear que este proyecto forma parte de una acción cultural es reconocer que es proactivo en una labor socializadora en la que se fomenta el espíritu crítico, se formulan alternativas a partir de la creatividad, se construye una experiencia de coparticipación y obliga a sus componentes a buscar formas de subsistencia y crecimiento para cada uno de los proyectos preexistentes. Se construye, en definitiva, un proyecto común que actúa de germen, vivero, herramienta o reactivador de cada proyecto que pertenece a los colectivos participantes.

\section{Subversiones, colaboraciones y redes en sus conclusiones}

La importancia de los proyectos realizados por Santiago Cirugeda, tanto en sus inicios en solitario, como posteriormente desde una estructura de trabajo en equipo, radica en la forma de afrontar el proyecto arquitectónico y creativo, tomando como punto de partida una vertiente crítica. La manera de resolverlo consiste en flirtear con la ilegalidad, buscando opciones que permitan ser desarrolladas aprovechando los vacíos legales.

14. Coelho, T. (2009): Diccionario crítico de política cultural. Cultura e imaginario. Barclona: Editorial Gedisa 
Otro de los valores de su trabajo se desprende del hecho de que, en buena parte, ha sido realizado durante el periodo de mayor crecimiento urbano que ha experimentado el Estado español, después de los movimientos migratorios internos posteriores a la guerra civil. Y su importancia no es precisamente el haber participado construyendo, sino oponiéndose al modelo constructivo que desde finales de los $90 \mathrm{y}$ hasta el 2010 imperó por todo el país, y del que muchos arquitectos se beneficiaron. Un periodo donde la mayoría de municipios se financiaron con los impuestos de las constructoras y las ventas de pisos. De hecho, uno de los trabajos que realizó junto con Guillermo Cruz, es el vídeo Spanish Dr€am, que desvela las causas y efectos de la burbuja inmobiliaria. ${ }^{15}$

En 2002 Rem Koolhas escribió un ensayo sobre el «espacio basura» a partir de la construcción urbana contemporánea. A lo largo del ensayo se muestra crítico con el aspecto uniformizado que adquieren las ciudades, que de un país a otro van transfiriendo mecanismos repetitivos desde una perspectiva universalizadora. Así, el fruto de la modernización no es la arquitectura moderna, sino lo que él llama «espacio basura». Es el fruto de lo que queda mientras la modernización está en marcha, con sus avances tecnológicos, sus brillantes invenciones, sus innovaciones infinitas. Con la complicidad de arquitectos, urbanistas políticos y constructores, hemos construido más que todas las generaciones anteriores juntas. «Hay más espacio basura en construcción en el siglo xxi que lo que ha sobrevivido del siglo xx. [...] Si la basura espacial son los desechos humanos que ensucian el universo, el "espacio basura" es el residuo que la humanidad deja sobre el planeta». ${ }^{16}$

Las mega estructuras, el uso de materiales brillantes, el envejecimiento de los materiales, la inmensidad de los centros comerciales, el pladur, la luz fluorescente, las escaleras mecánicas, todo el universo de elementos que forman parte de lo construido es parte aditiva del «espacio basura». «Restaurar, recolocar, reagrupar, reformar, renovar, revisar, recuperar, rediseñar, retornar (los mármoles del Partenón), rehacer, respetar: los verbos que empiezan por "re" producen "espacio basura"... El "espacio basura" será nuestra tumba. La mitad de la humanidad contamina para producir y la otra mitad contamina para consumir»». ${ }^{17}$

Desde estas reflexiones que propone Rem Koolhas podemos plantear que la obra, los proyectos, los procesos y los sistemas que propone Cirugeda escapan por

15. <https://www.youtube.com/watch?v=-8QoByoYcDM $>$ [Consulta:10 de junio de 2015].

16. Koolhas, R. (2004): Acerca de la ciudad. Barcelona: Ed. Gustavo Gili, p. 72.

17. Ibíd., p. 91. 
completo a la arquitectura que genera «espacios basura». Muchas de sus intervenciones son efímeras, la mayoría de ellas utilizan materiales fruto del reciclaje de otras arquitecturas y espacios obsoletos. La mayoría de ellas requiere un alto grado de implicación de personas que serán usuarias o gestoras de los espacios que se van a construir, por lo que el uso de estos espacios estarán cargados de sentido, identidad y complicidad. Muchas de sus intervenciones aprovechan situaciones transitorias, y el modelo constructivo no es el de grandes infraestructuras, iconografías que se imponen en la ciudad. El modelo se fundamenta en la construcción comunitaria, en la reparación social y la activación de procesos. Y su formalización adquiere sentido cuando es activadora de nuevos procesos.

La labor de Cirugeda en este contexto nos interesa porque es sumamente híbrida, tanto en su comportamiento como en su manera de llevarla a cabo. Constituye un ejemplo del paso del proyecto a la articulación sistémica, fundamentada en la complejidad de los elementos que pone en juego. Hemos analizado la forma en que ha llevado a cabo los proyectos desde sus inicios, estructurando el relato a partir de dos bloques que hemos denominado «estrategias subversivas» $\mathrm{y}$ «estrategias colaborativas».

Lo subversivo, lo colaborativo y la articulación de redes no constituyen tres estadios diferenciados ni tres categorías temporales, aunque se han ido configurando con el tiempo, a través de la experiencia y la madurez en la forma de afrontar los procesos. Lo subversivo y lo colaborativo y la construcción de redes queda incluido en una articulación sistémica de la práctica creativa. Lo subversivo puede ser una acción de guerrilla, kamikaze, cortoplacista, que combinada con lo colaborativo adquiere una dimensión más compleja, que obligatoriamente requiere ser más articulada. La estrategia sistémica que hemos planteado en relación a su trabajo, la hemos fundamentado en la combinación de las dos anteriores, pero también por la capacidad de empoderamiento ciudadano y por la posibilidad de inducir comportamientos auto-organizados.

Aunque a nivel teórico, e incluso a nivel práctico, todo parece encajar en la configuración de una estructura sistémica, la duda que se plantea es si la singularidad y la excepcionalidad del personaje pone en peligro la continuidad de un modelo de actuación replicable. Es decir, si la acción colectiva que conlleva la articulación de los proyectos es fruto de un comportamiento auto-organizado, o es consecuencia de una manera de hacer liderada y activada por un «marcapasos», que cuando deja de estar presente hace que la continuidad del proyecto se resienta o incluso se desvanezca. 


\section{Referencias}

Cirugeda, S. et al. (2010): Arquitecturas Colectivas. Camiones, Contenedores, Colectivos, Vibok, Sevilla.

— (2004): Situaciones Urbanas. Editorial Tenov, Barcelona.

Coelho, T. (2009): Diccionario crítico de política cultural. Cultura e imaginario. Editorial Gedisa, Barcelona.

Foster, H. (2006): «Chat Rooms//2004». En Bishop, Cl. (ed.): Participation, 190-195. Whitechapel Gallery. Cambridge, Massachusetts: The MIT Press, London.

Harvey, D. (2013): Ciudades rebeldes. Del derecho a la ciudad a la revolución urbana. Ediciones Akal, Madrid.

- (2008): El derecho a la ciudad. Disponible en: <http://kaosenlared.net> [Consulta: 10 de septiembre de 2015].

Koolhas, R. (2004): Acerca de la ciudad. Ed. Gustavo Gili, Barcelona.

Parramon, R. (2008): «Outskirts Artist» en The/End Magazine. Parallel Project n.1. Milano: Direct Arquitecture. Politics and Space. En $<$ https://www.youtube.com/watch? $\mathrm{v}=-8 \mathrm{Q}$ oByoYcDM $>$ [Consulta: 10 de junio de 2015].

SENNETT, R. (2009): El artesano, Anagrama, Barcelona.

- (2012): Juntos. Rituales, placeres y política de cooperación, Anagrama, Barcelona. 
